\title{
ESTRATÉGIAS EMPRESARIAIS PARA JORNAIS IMPRESSOS EM TEMPOS DE INTERNET: O CASO DA FOLHA DE SANTA CRUZ
}

\author{
Business Strategies for Printed Newspapers in Times of Internet: The Case of the Folha \\ de Santa Cruz
}

\author{
Douglas Wegner \\ Universidade de Santa Cruz do Sul -UNISC \\ dwegner@unisc.br
}

Alyne Sehnem

Universidade do Oeste de Santa Catarina - UNOESC

alynesehnem@hotmail.com

Submissão: 17/05/2012

Aprovação: 02/09/2013

\section{RESUMO}

O caso para ensino aborda a situação hipotética de um jornal impresso de âmbito regional que precisa desenvolver estratégias para fazer frente aos impactos da internet. As informações apresentadas refletem a situação de dezenas de jornais brasileiros de pequeno e médio porte que, apesar da sua tradição e credibilidade, passaram a enfrentar dificuldades relacionadas ao crescimento do número de usuários de internet e as facilidades de acesso a informações online, com queda no número de assinaturas e verbas de anunciantes. $\mathrm{O}$ caso de ensino inicia com o histórico do jornal Folha de Santa Cruz, sua trajetória de desenvolvimento e expansão na região de atuação. Na sequência, apresentam-se dados sobre a internet e resultados de uma survey realizada com 240 pessoas, que mostram os dilemas enfrentados atualmente pelos gestores de jornais impressos em função da influência da internet. Considerando o cenário apresentado, os diretores do jornal precisam tomar decisões estratégicas sobre como posicionar o jornal para minimizar a tendência de queda no número de assinantes e verbas dos anunciantes. Os estudantes são instigados a utilizar ferramentas para análise do ambiente, discutindo as tendências para o setor de mídia impressa e elaborando estratégias para a empresa descrita.

Palavras-chave: caso de ensino, internet, jornais, estratégia. 


\begin{abstract}
The teaching case discusses the hypothetical situation of a regional newspaper that needs to develop strategies to cope with the impacts of the Internet. The information presented reflects the plight of tens of Brazilian small and medium newspapers that began to face difficulties related to the growing number of Internet users. Despite their tradition and credibility, these newspapers have to handle with the drop in number subscriptions and advertisers' funds. The teaching case begins with the history of the newspaper Folha de Santa Cruz and its development and expansion. Following, we present data on the Internet and results of a survey with 240 people, which show the dilemmas faced by the managers of newspapers due to the influence of the Internet. Considering the scenario presented, the directors of the newspaper need to take strategic decisions about how to position the journal to minimize the downward trend in the number of subscribers and advertisers' funds. Students are encouraged to use tools to analyze the newspaper's business environment, discussing trends for the printed media and developing strategies for the company.
\end{abstract}

Key-words: Teaching case, internet, newspapers, strategy. 


\section{Introdução}

Naquela manhã, Roberto chegara ao prédio do jornal mais cedo do que de costume. Ainda estava escuro, mas as rotativas já estavam paradas e o jornal impresso durante a noite estava chegando à casa dos assinantes. Naquele dia seriam tomadas decisões importantes para o futuro do jornal e a noite de insônia era um prenúncio da tensão que marcaria a reunião com os demais diretores da empresa. Sozinho, no silêncio da sua sala, Roberto se esforçava para entender os impactos da internet para o jornal fundado por seu pai há mais de sete décadas e como as novas tecnologias estavam levando à queda do número de assinantes e de verbas publicitárias. Seu pai certamente saberia que decisões tomar naquela situação.

"Os jornais foram o grande palco da história do último século. Nenhum evento que despertasse atenção foi deixado de lado. Eles cumpriram, e ainda cumprem, papel fundamental no estabelecimento e consolidação de democracias ao possibilitar que as pessoas fiquem conectadas ao mundo que existe à sua volta"1. Embora tecnologias como o rádio e depois a televisão tenham se popularizado rapidamente, os jornais mantiveram sua importância como espaços para veiculação de notícias locais, discussão de temas regionais, fonte de informação sobre os acontecimentos do país e do mundo e estímulo aos negócios locais. "Representaram um espaço em que aqueles que procuram emprego e empresas, vendedores e compradores, analistas econômicos e as pessoas em geral, imobiliárias e o sonho da casa nova, encontravam uns aos outros. Os classificados de domingo eram verdadeiras lojas de departamento"2.

O que poderia modificar essa realidade? Nos últimos anos a internet tem representado um desafio significativo aos jornais impressos, tanto no que se refere aos hábitos de leitura das novas gerações quanto aos interesses dos anunciantes, demandando novas estratégias para a manutenção de sua viabilidade através da conquista de novos leitores e anunciantes. Para jornais que surgiram e se desenvolveram na era da notícia em papel, desenvolver estratégias que minimizem as ameaças da internet ou aproveitem suas oportunidades é um grande desafio. E esse era também o desafio que tirava o sono de Roberto: como fazer com que o jornal criado há décadas pelo pai pudesse sobreviver em tempos de internet? Aquele seria um dia de decisões. Um dia importante para o futuro do jornal.

\footnotetext{
${ }^{1}$ Fonte: ALCADIPANI, 2007, p. 31.

${ }^{2}$ Fonte: ALCADIPANI, 2007, p. 32
} 


\section{Um jovem visionário e o surgimento de um jornal}

João Fischer era um jovem sonhador. Recém casado e no auge dos seus 20 anos vislumbrava para o pequeno município de Santa Cruz do Sul, no interior do Rio Grande do Sul, um meio de comunicação popular de fácil acesso aos moradores da região. Era verão de 1938. Nacionalmente, vivia-se o período regido pela Constituição de 1937, absolutamente autoritária e centralizadora. O português era a única língua permitida pelo Governo de Getúlio Vargas, porém era praticamente desconhecida pela maioria das pessoas da colônia de Santa Cruz do Sul. O único jornal da cidade - Kolonie-, editado na língua alemã, estava prestes a ser extinto. No entanto, Fischer era um visionário. Queria que as pessoas tivessem acesso às informações e aos acontecimentos da região do Vale do Rio Pardo, uma vez que estavam isoladas do mundo devido à inexistência de um veículo de comunicação impresso na cidade. Percebeu que na situação imposta pelo governo havia uma possibilidade de atuação para um jornal criado por ele.

Graças às folhas douradas do tabaco, cultivado em pequenas propriedades rurais e vendido na cidade, a região em torno de Santa Cruz do Sul estava em pleno crescimento econômico e social. Precisava de um meio de comunicação que pudesse contar e registrar a história dessa promissora região a todo o estado do Rio Grande do Sul, ao mesmo tempo em que trazia as notícias da Capital e do restante do Brasil para a casa dos moradores locais.

Foi na mercearia da família que João ouviu de um importante político que um grupo de empresários queria estruturar uma editora na cidade. Pretendiam com isso que Santa Cruz do Sul tivesse um local para realizar as impressões de materiais de divulgação para as empresas. A informação deixou João excitado: "É isso que falta para que o jornal se torne realidade". Na mesma semana João procurou os empresários e fez uma proposta de parceria: ele utilizaria a capacidade ociosa das máquinas de impressão para tornar realidade um jornal local para manter bem informadas as comunidades da região.

Alguns meses de trabalho depois daquela reunião e João Fischer estava prestes a realizar o seu sonho. Ana Luisa, esposa de João, antes receosa da aceitação da ideia de seu marido, agora estava envolvida com o processo de produção do jornal, seleção das matérias e busca por anunciantes. Assim, em março de 1939 foi lançada a primeira edição do Jornal Folha de Santa Cruz, em grande evento com a participação de autoridades públicas, representantes das cidades vizinhas, comerciantes, representantes de associações e cooperativas da região.

Inicialmente a Folha de Santa Cruz era um semanário. Devido às dificuldades que todo novo empreendimento possui, à necessidade de consolidação do jornal na comunidade santacruzense, da conquista de seu público e seus patrocinadores e anunciantes, o jornal começou andando a passos cautelosos. Fischer, no entanto, sabia que essa situação seria passageira e que logo o jornal seria um diário. O sucesso e a fidelização dos leitores eram evidentes! Muitas empresas buscavam no jornal um meio para a divulgação dos seus produtos e serviços.

Os anos foram passando e, na comemoração dos 5 anos do lançamento da primeira edição da Folha de Santa Cruz foram adquiridas as primeiras máquinas próprias e o jornal tornou-se bi semanário. $\mathrm{O}$ crescimento e a representatividade que o jornal estava conquistando eram visíveis. No ano de 1947 a periodicidade do jornal mudou novamente. De bissemanário o jornal passou a circular na região três vezes por semana. No ano seguinte foi preciso investir em infraestrutura para comportar as novas máquinas que estavam sendo adquiridas. A partir da aquisição desse novo maquinário o jornal passou a ser impresso, dobrado e encartado, 
diminuindo os defeitos e problemas que anteriormente aconteciam. A qualidade do jornal melhorou, ganhando ainda maior destaque na região do Vale do Rio Pardo.

No entanto, essas ampliações demandavam um grande investimento de capital. Assim, para suportar os custos de implantação dos equipamentos e da infraestrutura, a empresa transformou-se em uma sociedade anônima. A partir da sociedade o jornal também passou por uma reestruturação. Como sua área de abrangência havia aumentado muito desde seu lançamento, fazia-se necessária uma revisão no seu nome. Antes entregue somente na cidade e arredores, agora o jornal embarcava cedo nos ônibus que iam para o interior do município e cidades vizinhas, para que um número maior de famílias pudesse ter acesso às notícias. $\mathrm{O}$ Jornal Folha de Santa Cruz tomou as proporções de toda a região do vale do Rio Pardo. A mudança do nome para uma abrangência maior refletia uma nova estratégia. Surgia então a "Gazeta do Vale". Os ânimos dos acionistas estavam em alta. Decidiu-se pela publicação do jornal de terça a sábado, totalizando cinco impressões semanais. Nos 30 anos que se seguiram foram realizados mais investimentos no Jornal Gazeta do Vale. Roberto, filho de João e Ana Luisa, participava da administração do Jornal como sucessor de seus pais. 


\section{A internet e as mudanças no ambiente empresarial: dilemas para a Gazeta do Vale}

O centro administrativo do Jornal Gazeta do Vale fica na parte central da cidade de Santa Cruz do Sul, onde funciona há várias décadas. Na parede à esquerda de quem chega à recepção, dois grandes quadros imediatamente chamam a atenção: em preto e branco, uma foto do fundador do jornal, João Fischer, olhar sério e penetrante; e uma ampliação da capa da primeira edição do jornal, de março de 1939. As ideias do jovem fundador continuam vivas na cultura da empresa, com a convicção de que o jornal que chega cedo à casa dos assinantes é um ritual que sempre fará parte da vida das pessoas.

Poucos são os jornais que circularam ininterruptamente por décadas e a Gazeta do Vale se orgulha da sua trajetória. De jornal semanal, com notícias locais e classificados, há quase trinta anos passou a ser um jornal diário, com visual moderno e matérias que cobrem desde as informações locais e regionais até os principais fatos internacionais. Há dez anos o jornal conta também com impressão colorida, tendo sido um dos primeiros do interior do estado a adotar essa tecnologia. As mudanças que ocorreram na história do Jornal Gazeta do Vale foram implementadas para que o jornal se adequasse às exigências do público e do mercado. Entre as estratégias bem sucedidas que marcaram a história recente da empresa está a participação em uma rede de cooperação formada por jornais estaduais do interior do Rio Grande do Sul. A ideia surgiu em uma reunião da Associação de Diários do Interior e foi acolhida por quinze jornais, que constituíram uma associação com o objetivo de potencializar seus negócios. De maneira cooperativa, esses jornais estabeleceram a produção conjunta de matérias de interesse geral e cadernos especiais, para veiculação simultânea, com ótimos resultados. Além disso, passaram a negociar conjuntamente a compra de suprimentos, especialmente papel para a impressão, gerando significativa redução de custos para os participantes.

Apesar do crescimento demográfico na região de atuação do jornal, nos últimos cinco anos o número de assinaturas e exemplares vendidos tem se mantido relativamente estável. Muitos pequenos municípios criados na região viram nascer seus próprios jornais locais. Ainda que pequenos e limitados, esses jornais eram capazes de relatar fatos de âmbito local e mobilizar suas comunidades, ocupando o espaço de veículos de comunicação um pouco mais distantes, como a própria Gazeta do Vale. Além desse movimento, as tendências globais de crescimento da internet como fonte de informações, tem preocupado muito o herdeiro do fundador. Roberto nasceu e cresceu em um mundo analógico, como seus pais, mas observando seus próprios filhos percebe que há mudanças significativas em curso, geradas pela tecnologia da informação.

Mais do que a preocupação com os pequenos concorrentes regionais, o impacto da internet para o Jornal Gazeta do Vale seria a pauta principal da reunião semanal dos diretores. Há trinta dias ficara decidido que naquela reunião os diretores encaminhariam decisões estratégicas para o futuro do jornal, especialmente quanto a como se posicionar em relação às ameaças e oportunidades representadas pela internet. Além disso, decidiram contratar uma consultoria que elaborasse uma pesquisa de mercado sobre o comportamento dos leitores de jornais impressos e acesso de sites de notícias. A apresentação dos resultados dessa pesquisa na reunião deveria trazer informações relevantes aos diretores do jornal. $\mathrm{O}$ sentimento coletivo na empresa era que o tempo para a tomada de decisões estratégicas estava se esgotando rapidamente. 


\section{Crescimento da internet no Brasil e consequências para os jornais impressos}

O Brasil possui uma população de usuários de internet estimada em mais de 80 milhões de pessoas a partir de $12 \operatorname{anos}^{3}$, dos quais 40 milhões acessam a internet de suas casas ou do trabalho. Aproximadamente $87 \%$ dos internautas brasileiros acessam a internet semanalmente. A entrada da classe $\mathrm{C}$ para o grupo de internautas deve manter o intenso ritmo de crescimento do número de usuários residenciais de internet nos próximos anos. Os brasileiros também se destacam entre os usuários que passam mais tempo conectados, em pesquisas comparativas com outros países.

Praticamente todos os segmentos de negócio têm sido afetados direta ou indiretamente pelo rápido crescimento do número de usuários da internet. A mídia impressa tem sido particularmente desafiada pelo novo cenário competitivo, em razão da facilidade de acesso aos conteúdos informacionais através da internet. Em 2010, uma notícia causou impacto: o tradicional Jornal do Brasil, fundado em 1891, passou a ser o primeiro jornal brasileiro de grande circulação a deixar de existir em sua versão impressa. A perecibilidade do produto é uma das principais características dos jornais impressos. "Uma das maiores máximas dessa indústria é que 'ninguém paga pelas notícias de ontem'. Por isso, para prosperar economicamente, o produto demanda a fidelidade absoluta de seus leitores, que precisam comprá-lo diariamente nas bancas ou se comprometer com o produto por longo prazo ao comprar uma assinatura",4.

Em diversos países as tendências apontam queda na circulação de jornais impressos. No Brasil, dados compilados pelo Instituto Verificador de Circulação (IVC) apontam que, em 2009, a circulação somada dos 20 maiores jornais brasileiros caiu 6,9\%. "Nos Estados Unidos, em 1964 quase 81\% dos adultos liam um jornal diariamente. Em 2004, esse percentual caiu para 52,8\%. Na França, entre 1972 até 2001, as vendas do produto caíram 40\%. No Reino Unido, entre 1999 e 2002, os jornais perderam cerca de 5 milhões de leitores" ". Dados coletados pela Associação Mundial de Jornais (WAN) confirmam as tendências de queda de leitura de jornais em diversos países do mundo.

No Brasil, pesquisas mostram que decresce tanto o número de leitores como o tempo que estes dedicam à leitura de um jornal. Se em 2001 ainda eram vendidos 62,2 jornais por mil habitantes, em 2005 esse número era de apenas 45,3 exemplares ${ }^{6}$. Essa redução pode estar relacionada tanto à migração dos leitores para outros meios quanto ao perfil dos novos leitores, que preferem a internet ao jornal impresso. Também o tempo dedicado à leitura de jornais caiu consideravelmente em cinco anos. A vida moderna faz com que o tempo seja um recurso escasso, em que o acesso imediato a informações sintetizadas e atualizadas representa uma vantagem. Para os indivíduos da era digital, aguardar pelo jornal que traz as notícias do dia seguinte faz pouco sentido, quando essas mesmas informações estão disponíveis com antecedência. Além disso, para as gerações que cresceram na era digital, acostumadas ao videogame e ao computador, "o jornal impresso pode revelar-se um meio opaco, inerte e desinteressante" .

A internet modificou também as decisões das empresas que tradicionalmente utilizavam os jornais impressos para divulgar seus produtos e se comunicar com o mercado.

\footnotetext{
${ }^{3}$ Fonte: F/NAZCA, 2010.

${ }^{4}$ Fonte: ALCADIPANI, 2007.

${ }^{5}$ Idem.

${ }^{6}$ Fonte: SANT'ANNA, 2008.

${ }^{7}$ Fonte: SANT'ANNA, 2008, p. 20.
} 
"Os grupos que sempre tiveram os jornais como espaço obrigatório de interação podem potencialmente se relacionar diretamente de forma mais eficiente e rápida. Os classificados não têm mais tanto apelo em um mundo em que qualquer produto está a um clique de distância. As ferramentas de busca possibilitam a comparação de preços em inúmeros canais de venda ao mesmo tempo" ". As novas tecnologias abriram caminhos oferecendo opções para os anunciantes chegarem diretamente aos clientes, sem pagar o pedágio cobrado pelos jornais. "Com a proliferação das mídias cresceram também os meios em que anúncios e propagandas podem ser feitos. Com isso, as verbas publicitárias ficaram muito mais dispersas entre os diferentes meios de comunicação" "

${ }^{8}$ Fonte: ALCADIPANI, 2007, p. 34.

${ }^{9}$ Idem. 


\section{A reunião da diretoria: a Gazeta do Vale precisa tomar decisões estratégicas}

Há algum tempo Roberto vinha refletindo sobre os rumos que o jornal criado por seu pai há mais de sete décadas deveria seguir, mas essa não era uma decisão que deveria tomar individualmente nem baseada na intuição. Por isso, havia encomendado uma pesquisa de mercado que seria apresentada naquele dia para os diretores do jornal. A reunião prometia ser tensa. Era início de mais um dia frio de inverno no sul do Brasil e já estavam todos na sala de reuniões. Roberto, os diretores de finanças, TI, comercial e o editor-chefe compunham o grupo. Desses, o editor-chefe e os diretores de finanças e comercial eram também acionistas minoritários do jornal. Cada um tinha sua história naquele jornal e por mais que pudessem ter pontos de vista diferentes, desejavam a continuidade e prosperidade da empresa. Em oportunidades anteriores os diretores já haviam manifestado opiniões diferentes sobre as estratégias que o jornal deveria adotar para se adaptar ao novo cenário. Roberto já podia prever as discussões, os pontos de vista divergentes e a dificuldade de chegar a um consenso. A simples ideia de que precisaria decidir sem o apoio irrestrito de todos os diretores, que acompanhavam o jornal há muito tempo, lhe causava receio.

Roberto iniciou a reunião entregando aos participantes os resultados da pesquisa encomendada:- Como sabem, solicitamos uma pesquisa de mercado à consultoria Mindset sobre a influência da internet nos hábitos de leitura das pessoas. Nossas decisões sobre os rumos do jornal precisam ser fundamentadas e não baseadas em sentimentos ou préconcepções. Gostaria que iniciássemos analisando os resultados da pesquisa encomendada.

Todos leram silenciosamente o documento entregue por Roberto (Anexo A), que observava as reações enquanto revisava aqueles dados que lhe causavam inquietação. Os dados mostravam que os jovens liam menos jornais, utilizavam a internet como fonte preferencial para obter informações sobre quase todos os assuntos, embora muitos deles tivessem acesso a jornais impressos, e a grande maioria utilizava redes sociais frequentemente. Como sempre fazia, Roberto preferia ouvir a opinião de todos antes de emitir a sua. A discussão estava aberta e o diretor de finanças tomou a palavra. 
Anexo A: Resultados da pesquisa de mercado

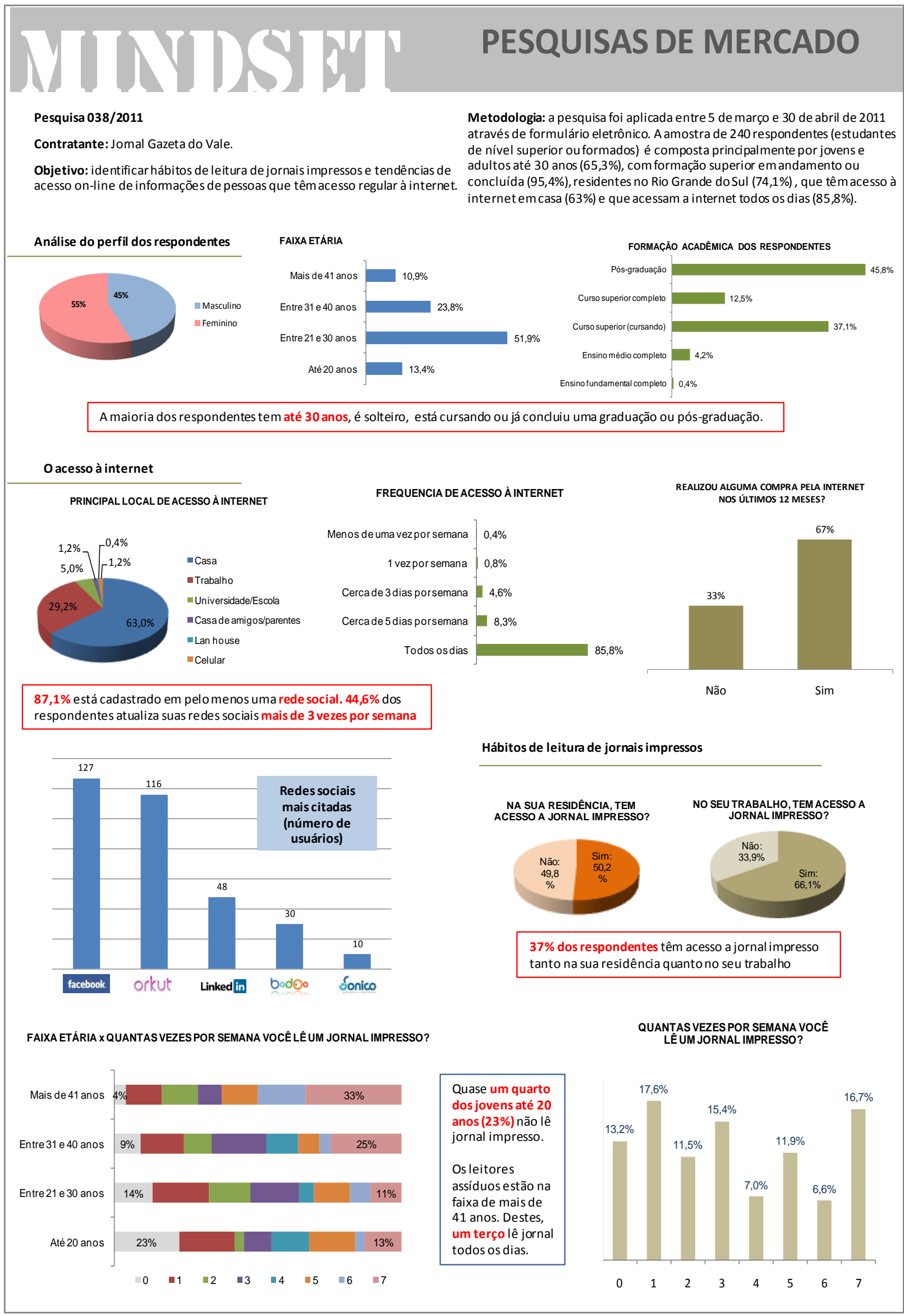




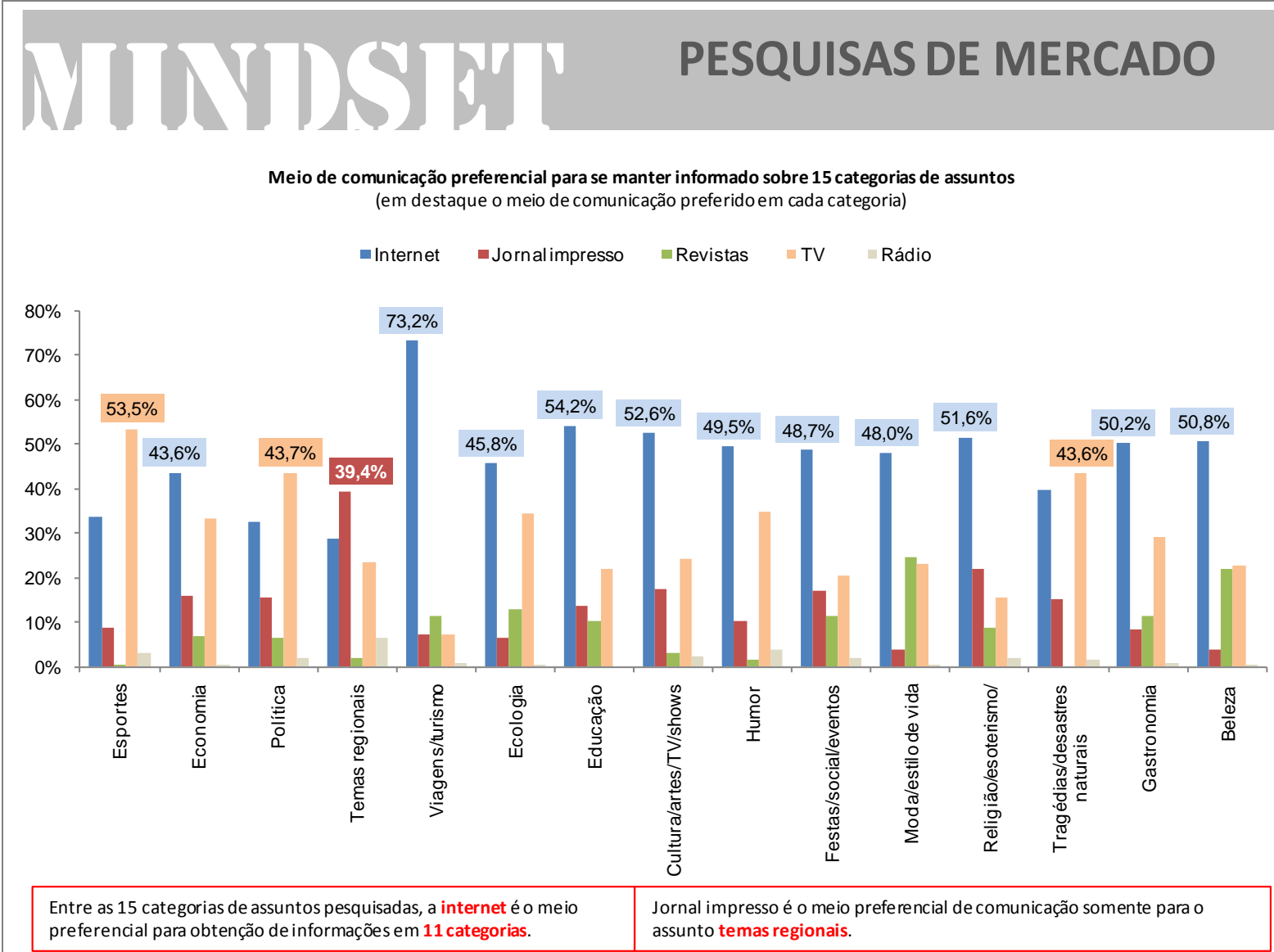

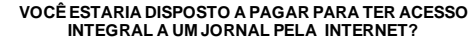
INTEGRAL A UM JORNAL PELA INTERNET?

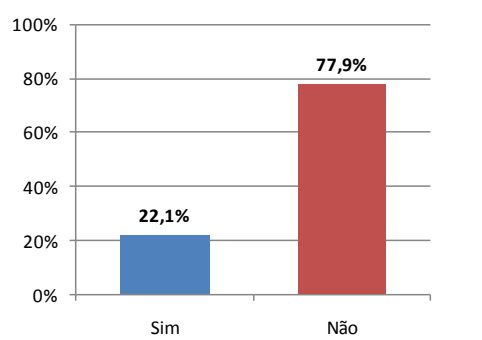

A internet está muito associada à ideia de gratuidade, à obtenção de informações sema necessidade de pagar por elas.

A quantidade de fontes distintas de informações disponíveis na web faz com que as pessoas estejam menos propensas a pagar por elas.

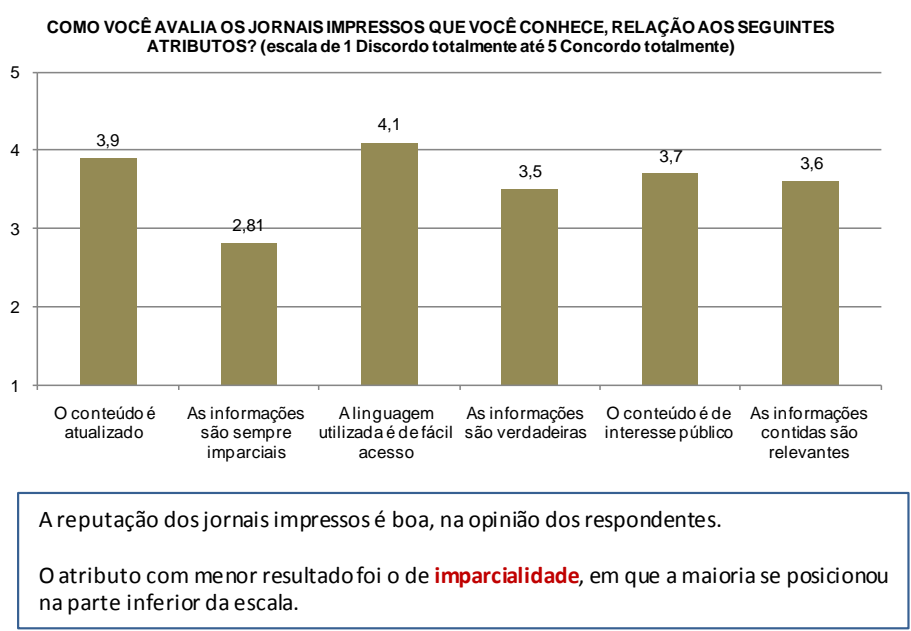

Análise dos consultores: A internet vem ocupando espaço crescente na vida das pessoas. A pesquisa revelou hábitos de um grupo de brasileiros que tende a crescer nos próximos anos, à medida que mais pessoas acessam o ensino superior e se conectam à internet.Manter-se informado através da internet é um hábito desse grupo, embora a maioria tenha acesso a um jornal impresso em casa ou na empresa. Entre os jovens, é significativamente menor o número de dias por semana que lêem um jornal impresso. A maioria dos respondentes utiliza pelo menos uma rede social; um grande número deles utiliza mais de uma. Trata-se de um novo canal de relacionamento e comunicação, que integra cada vez mais funcionalidades e gera possibilidades de negócios. É tarefa dos gestores de empresas pensar em como explorar essas oportunidades.O que fica claro é que poucos dos respondentes estariam dispostos a pagar para ler um jornal pela internet. Jornais impressos continuam com uma boa reputação, mas simplesmente não são mais o meio preferido para obter informações. No entanto, a pesquisa mostra que os assuntos regionais são um tema a ser explorado pelos jornais impressos, enquanto os demais temas são acessados preferencialmente através da internet ou da televisão. A internet reserva muitas oportunidades, no entanto reserva também ameaças para aqueles que não souberem enxergar suas potencialidades.

Santa Cruz do Sul, julho de 2011 - Consultoria Mindset - Pesquisas de Mercado 
- Não se pode negar que estes números apresentam tendências preocupantes. Está muito claro que há um deslocamento dos leitores de jornais para a internet, em especial o público mais jovem. Por isso, penso que precisamos passar por um momento de readequação da nossa estrutura de custos. Não podemos assistir à queda de circulação de nosso jornal sem tomar medidas de ajuste. Há tempos percebo que o sucesso do jornal no passado, o crescimento do volume de anúncios e assinaturas fez com que deixássemos de nos preocupar com os custos. Fizemos altos investimentos em equipamentos de impressão e hoje temos uma grande capacidade ociosa. Precisamos pensar maneiras de utilizar essa capacidade não aproveitada. Além disso, quero me manifestar quanto ao nosso quadro de pessoal. Por que precisamos de tantos jornalistas? Vocês não concordam que o jornal poderia funcionar da mesma forma com uma folha de pagamento bem menor? E também penso que nossos jornalistas poderiam trabalhar no desenvolvimento de outros produtos, como revistas especializadas, revistas setoriais ou edições específicas sobre determinados temas. Seria uma forma de melhor aproveitar nossos recursos humanos e técnicos.

O editor-chefe do jornal foi o segundo a falar: - Estou neste jornal há quase quarenta anos. Quanto tempo trabalhei com seu pai, Roberto? Esse homem foi um visionário, apaixonado pelo jornal. Assim como você, aprendi com ele tudo que sei sobre o funcionamento de um jornal. Talvez vocês não lembrem, mas na edição de comemoração dos 50 anos do jornal ele escreveu um editorial em que dizia que 'nenhum meio de comunicação vai substituir a experiência de abrir a porta de casa pela manhã e encontrar um jornal que traz para dentro do lar as notícias da região e do mundo, para serem lidas durante o café da manhã'. Essa frase me marcou muito e, sinceramente, não acredito que a internet vai afetar nosso negócio. A pesquisa é interessante, mas não retrata nossa realidade regional. Basta ver a amostra pesquisada, que é de pessoas que acessam a internet quase todos os dias. Isso é uma minoria nesta região. A grande massa da população nunca terá acesso à internet. Além disso, qual a profundidade de uma matéria de dez linhas na internet ou de alguns caracteres digitados em uma rede social? A internet atualiza, mas não oferece a profundidade e interpretação de um jornal. Você vê a notícia, mas nada como um bom e velho jornal para ter a informação completa e aprofundada. Não acho que devemos fazer grandes mudanças estratégicas agora. Aliás, acho até que iríamos nos arrepender se colocássemos dinheiro em uma aposta como a internet. Sou radicalmente contra qualquer movimento nesse sentido.

As palavras do editor-chefe ecoaram como trovões na sala de reuniões. Embora ele fosse muito respeitado em razão do longo tempo de prestação de serviços ao jornal e o fato de ser acionista, os segundos de silêncio que se passaram após sua enfática manifestação pareceram um sinal de reprovação, ou pelo menos de que sua leitura das mudanças que estavam em curso parecia equivocada. $\mathrm{O}$ diretor de TI foi o próximo a pedir a palavra.

- Bem, eu estou há menos tempo aqui, mas minha opinião é divergente. As tendências apontadas pela pesquisa são bastante sérias para o nosso negócio. É claro que estamos no interior do estado, com um nível menor de acesso à internet do que nos grandes centros, mas acho que esse processo é irreversível e o governo está empenhado em aumentar o nível de digitalização da população brasileira. Vejam os dados: principalmente os jovens, que são o futuro do nosso negócio, estão usando a internet de uma forma muito intensa e é através dela que se mantêm informados. Eles estão nas redes sociais, se relacionam virtualmente, usam Twitter para saber o que está acontecendo no mundo. Um número cada vez maior de pessoas considera o acesso à informação um bem gratuito e não estão dispostas a pagar por notícias que já viram na internet. Acredito que precisamos criar uma estratégia para aproveitar as potencialidades da web enquanto temos fôlego financeiro. Não podemos esperar a crise para lamentar o fato de não termos agido a tempo. Aliás, quero deixar registrado que estamos correndo um grande risco de que outra empresa de mídia seja a primeira a marcar território 
com um portal de notícias na nossa região. Temos uma marca consolidada, que tem história e credibilidade. Por que não estendê-la à internet? Nosso negócio é a informação, não o papel. O papel é apenas o meio, e não significa que não possa mudar.

O Diretor Comercial estava inquieto em sua cadeira, aguardando o momento de se manifestar: - Estava ouvindo os argumentos de vocês e acho importante trazer alguns elementos adicionais para a discussão. Em reuniões anteriores já relatei a este grupo que, além do número de assinaturas e venda de jornais, estamos verificando uma tendência de queda no número de anúncios e no volume de verbas publicitárias que as empresas destinam para anúncios em jornal. Quero lembrar que os anúncios representam $60 \%$ de nossa receita total. Ora, mas então o que está acontecendo? Na prática, é uma dispersão das verbas publicitárias. Há alguns anos éramos o único jornal da região e, bem é verdade, continuamos sem grandes concorrentes diretos, mas há vários pequenos jornais nos municípios do entorno que absorvem parte dos anúncios que antes eram nossos. São jornais focados em notícias locais, em nível que temos dificuldades de alcançar porque são informações que interessam apenas ao público mais próximo dos fatos. Sem falar que até aqui em Santa Cruz do Sul já existem sites de classificados, portais para oferta de veículos e as imobiliárias possuem catálogos eletrônicos. E pior: nos anúncios da internet é possível medir o clickthrough e saber exatamente quantas pessoas acessaram um anúncio, algo que nunca será possível na mídia impressa. O sucesso dos micro anúncios nas buscas do Google é um exemplo. Enfim, penso que precisamos agir rapidamente, embora não consiga visualizar claramente as ações que deveríamos seguir. Sinceramente, não posso concordar com a ideia de simplesmente reduzir custos ou permanecer imóvel, esperando a maré mudar a nosso favor sem agir. Precisamos tomar decisões estratégicas para ontem.

O Diretor de TI pediu para complementar: - Também não devemos esquecer que os principais jornais estaduais e nacionais estão disponíveis na internet... mesmo que não publiquem suas edições na íntegra, as principais notícias estão lá. A Zero Hora e o Correio do Povo, por exemplo, passaram a ser nossos concorrentes diretos, assim como outros portais de notícias como Globo e Terra. Esses portais trazem as principais notícias do estado e do país... gratuitamente. Nossa vantagem é a identificação com a região e a capacidade que temos de apresentar as notícias de uma perspectiva mais próxima ao nosso leitor.

Roberto tinha se limitado a ouvir as manifestações de cada um. $\mathrm{O}$ fato de que três deles eram acionistas do jornal também poderia ter implicações para a tomada de decisão. Conhecia muito bem seus diretores e já imaginava que as propostas seriam divergentes, mas estava preocupado com a leitura dos dados feita por alguns deles. As mudanças provocadas pela internet e as tendências reveladas pelos dados representavam ameaças ao formato do seu negócio, mas por que não pensar nelas como oportunidades? Várias perguntas passaram pela mente de Roberto nos breves segundos de silêncio que se seguiram à fala dos diretores e seriam a pauta da discussão. A reunião não poderia terminar sem decisões estratégicas para a Gazeta do Vale. Algumas questões ocupavam a mente de todos os que estavam naquela sala:

1) Que cenários se apresentam para o jornal e que estratégias o jornal deveria adotar para continuar sendo uma referência regional em tempos de internet?

2) Que caminhos deveriam seguir sem canibalizar o jornal impresso, que bem ou mal continuaria sendo o principal negócio da empresa por um bom tempo?

3) Como atender simultaneamente o público que se mantém interessado em jornais impressos e atingir a massa de jovens que raramente lê um jornal impresso? 


\section{Notas de Ensino}

\section{1 Área de conhecimento a que se destina o caso}

O caso foi elaborado para utilização em disciplinas de Estratégia Empresarial, Planejamento Estratégico e Empreendedorismo, em cursos de graduação.

\subsection{Obtenção dos dados}

O jornal descrito no caso e seu histórico de desenvolvimento são fictícios. As informações necessárias para a elaboração do caso para ensino foram obtidas a partir de dados secundários sobre o segmento de jornais impressos, indicados abaixo, e por meio da aplicação de uma survey sobre hábitos de leitura de jornais. O questionário de pesquisa foi aplicado através de questionário eletrônico e respondido por 240 pessoas entre 5 de março e 30 de abril de 2011.

\subsection{Objetivos pedagógicos}

O caso tem como objetivo discutir o impacto da internet para os negócios e a necessidade de reorientação estratégica de segmentos tradicionais, ao mesmo tempo em que instiga a aplicação de ferramentas de diagnóstico e desenvolvimento de estratégias. O docente pode, por exemplo, estimular a utilização de ferramentas para análise do ambiente concorrencial, como o modelo das cinco forças de Porter, para análise dos requisitos para obtenção de vantagens competitivas em um ambiente de negócios em rápida mudança. $\mathrm{O}$ caso também é propício para discussão e proposição de estratégias empresariais e estratégias interorganizacionais, a partir do cenário analisado.

Em seu estudo intitulado "How Competitive Forces Shape Strategy", Porter (1988), trata da ação estratégica frente às forças competitivas que vão além da ideia simplista da concorrência direta. Além do setor que compete entre os concorrentes existentes, deve-se considerar também as ameaças de novos entrantes, o poder de barganha dos fornecedores e clientes e a ameaça de produtos ou serviços substitutos. Ele aplica essa visão da competição tanto ao setor industrial quanto ao setor de serviços e à venda de produtos. Para Porter (1988) duas são as grandes questões: "Forças Combatentes" e "Formulação da Estratégia". Na primeira, ele enquadra os temas da ameaça dos novos entrantes, as condições de mudança, o poder dos compradores e fornecedores, a ação estratégica, os produtos substitutos e, por fim, a corrida pela posição. Na segunda, ele classifica a temática do posicionamento da empresa, a influência sobre o equilíbrio, e, como explorar a mudança no setor.

Em se tratando de competição para a entrada, Porter (1988) considera que os novos entrantes concorrem com recursos substanciais de um setor e que a entrada destes dependerá das barreiras e da reação dos concorrentes. Ele destaca seis fontes de barreiras: a economia de escala; a diferenciação de produto; a necessidade de capital; as desvantagens de custo independente do porte; o acesso a canais de distribuição; e a política governamental. No que se refere às condições de mudança para uma entrada, ele entende que a estratégia muda à medida que mudam as condições, por exemplo, tecnologias, patentes. Decisões estratégicas em um grande segmento de setor exercem impacto nas condições determinantes de ameaça de entrada. Já as contribuições advindas do poder dos fornecedores podem se dar por meio de aumento de preços ou redução da qualidade das mercadorias ou serviços. Os clientes, 
igualmente, podem forçar os preços para baixo ou demandar maior qualidade jogando um concorrente contra o outro. Neste sentido, dentro da ação estratégica a empresa pode e deve escolher a quem vender, pois dependendo da situação de custos, vender para muitos pode ser considerada atitude quase suicida, ou seja, a empresa se tornará vulnerável. Porter (1988) ainda chama a atenção para os produtos substitutos, com destaque para aqueles sujeitos as tendências de melhoria do trade-off preço/desempenho visando o produto do setor ou que sejam produzidos por setores com altos lucros. A corrida pela posição, por sua vez, gera a rivalidade entre os concorrentes usando táticas como as de competição de preços, lançamentos e golpes de publicidade.

Em suma, Porter (1988) propõe uma forma de análise de cenário ao se desenvolver a formulação da estratégia e assinala para as questões chave que devem ser levadas em consideração pelo estrategista. Dentre elas destaca o posicionamento da empresa, onde afirma que o conhecimento das próprias capacitações acentuará as áreas onde a empresa deve confrontar a competição e onde deve evitá-la. Da mesma forma, diz que o estrategista pode influenciar o equilíbrio ao lidar com as forças que impulsionam a competição partindo para a ofensiva. De forma semelhante, diz que se devem explorar as mudanças no setor, pois as tendências da mais alta prioridade estratégica são aquelas que afetam as mais importantes fontes de competição no setor e aquelas que alçam novas causas para a linha de frente. Nessa linha, a existência dos produtos substitutos que desempenham as mesmas funções que os produtos ou serviços analisados é uma condição básica que limita o montante de valor que uma indústria pode criar. A análise da ameaça de substituição de produtos pelo lado da demanda deve focalizar as funções desempenhadas pelos clientes, e não apenas a similaridade física dos produtos.

\subsection{Questões para discussão do caso em sala de aula}

a. Como uma definição ampla do negócio da empresa pode auxiliá-la a reorientar sua estratégia?

b. Como as cinco forças do Modelo de Porter atuam na situação apresentada e quais delas possuem maior influência na dinâmica do setor?

c. Que recursos e capacidades o jornal possui e quais precisaria desenvolver para criar uma estratégia de inserção na internet?

d. Qual seria a sua sugestão de escolha estratégica com relação ao futuro do Jornal Gazeta do Vale se você fosse um dos sócios?

e. Quais os riscos e oportunidades para a inserção do jornal Gazeta do Vale em meio virtual?

f. Que sequência de ações estratégicas você proporia ao jornal para adotar uma estratégia de entrada na internet sem canibalizar o jornal impresso?

g. Que estratégias interorganizacionais o jornal poderia utilizar para minimizar as ameaças representadas pela internet e diminuir os riscos associados à atuação individual?

\subsection{Possíveis soluções para o caso}

A análise do ambiente competitivo do jornal, utilizando o modelo das cinco forças de Porter, revela que as principais forças do setor são a ameaça de novos entrantes e produtos substitutos, em razão de mudanças tecnológicas. Jornais impressos conseguem estabelecer 
poucas barreiras à entrada de competidores on-line, considerando que o custo de criar e manter uma página na internet é quase irrisório. Ao mesmo tempo, com a tecnologia os leitores passaram a ter acesso a jornais de todo o país e do mundo, o que aumentou a concorrência do setor. Embora os clientes (leitores do jornal) não disponham, individualmente, de grande poder de negociação, os baixos custos de troca representam uma dificuldade para os jornais impressos, potencializados com a facilidade de acesso a informações gerada pela internet. Além disso, novos serviços que podem substituir os jornais impressos vêm sendo desenvolvidos, como o acesso a informações por meio de smartphones e tablets.

Ao mesmo tempo, deve-se considerar que o jornal em questão possui um longo histórico, o qual permitiu acumular recursos e capacidades valiosos para concorrer no setor. A reputação adquirida em várias décadas, o reconhecimento da marca em nível regional e a inserção na comunidade do Vale do Rio Pardo são recursos importantes no desenvolvimento de estratégias competitivas. Essa análise serve de orientação para que a empresa repense a definição do negócio em que atua. Na visão estreita, a empresa poderia concluir que atua no negócio de jornais impressos, enquanto uma visão ampla levaria à conclusão de que ela está, de fato, no negócio de informações ou notícias. O papel é apenas o meio, não o ponto central do negócio. Como destaca o editor do jornal The New York Times, citado por Sant'anna (2008), “jornais (newspapers) não podem ser definidos por sua segunda palavra - papel (paper). Eles têm de ser definidos pela primeira - notícia (news). Todos nós devemos nos tornar agnósticos em relação ao método de distribuição. (...) Não me importa quando rodaremos nossa última edição de notícia impressa. Continuaremos sendo a grande fonte de notícias e de informações neste país e no mundo".

A partir dessa análise podem ser propostas algumas estratégias para o jornal:

- Adoção de estratégia de redução de custos e parceria com agência de notícias: a estratégia proposta pelo diretor de finanças tende a gerar resultados de curto prazo, com a redução da folha de pagamento e redução da estrutura, mas deve causar problemas no médio e longo prazos, à medida que afeta a qualidade do que é produzido e publicado e pode arranhar a reputação do jornal como veículo de comunicação reconhecido na região. A redução do número de reportagens sobre temas e acontecimentos regionais pode enfraquecer a imagem do jornal e sua inserção na comunidade local.

- Diferenciação do jornal impresso e desenvolvimento de novos produtos impressos, sem adoção de uma estratégia na internet: trata-se de uma estratégia arriscada, haja vista as tendências observadas na pesquisa sobre hábitos de leitura. $\mathrm{O}$ jornal poderia desenvolver reportagens aprofundadas, colunas opinativas, comentaristas setoriais e reforçar temas regionais, com novos conteúdos além das notícias diárias. Além disso, poderia utilizar os recursos internos (repórteres, editores e parque gráfico) para produzir novos materiais, como revistas sobre setores específicos, edições especiais e materiais de interesse de empresas e comunidade regional.

- Disponibilização do jornal impresso na internet: trata-se da primeira estratégia utilizada pelos jornais impressos a partir do advento da internet. A edição impressa passou a ser disponibilizada em PDF na internet, inicialmente de forma gratuita e posteriormente mediante assinatura eletrônica. Trata-se de uma estratégia de baixo custo, porém os números da pesquisa mostram que somente $22 \%$ das pessoas estariam dispostas a pagar para ter acesso a um jornal completo pela internet. Por outro lado, essa estratégia pode ser 
interessante para atrair tráfego ao website do jornal, com a possibilidade de obter receitas de publicidade on-line no futuro.

- Criação de um portal de conteúdo e notícias: através desta estratégia a empresa poderia obter sinergias entre o jornal impresso e o portal, utilizando focos, temas e linguagem diferentes em cada canal. A empresa deslocaria seu negócio em direção ao provimento de conteúdo, em vários meios. $\mathrm{O}$ portal pode se viabilizar economicamente através de anúncios eletrônicos, ao invés de assinaturas. Através de uma linguagem diferenciada e temas de interesse para o público jovem, a empresa pode atingir um público que atualmente não acessa o jornal impresso. Esta alternativa poderia envolver também a adoção de estratégias interorganizacionais, através de parceria com outros jornais regionais para viabilização de um portal desenvolvido e gerenciado de forma cooperativa. Ou ainda, através da cooperação poderiam ser desenvolvidas matérias conjuntas, para veiculação em portais próprios de cada jornal.

O caso não possui uma resposta única ou correta, exigindo dos alunos criatividade para a criação de alternativas e respectivos argumentos de defesa, desde que fundamentadas com a utilização de ferramentas de análise estratégica. A combinação de estratégias também é uma possibilidade. Cabe ao professor estimular a discussão sobre as vantagens e desvantagens de cada alternativa.

\subsection{Estratégias de ensino}

Para melhor aproveitamento do caso em sala de aula, sugere-se que o professor aborde previamente os seguintes conteúdos: métodos de análise da indústria, especificamente o Modelo das Cinco Forças de Porter; a teoria da Visão Baseada em Recursos, para fundamentar a análise dos recursos e capacidades organizacionais; conceitos de estratégias deliberadas e emergentes; tipologias de estratégias, como por exemplo as estratégias genéricas de Porter e a tipologia proposta por Mintzberg, bem como estratégias interorganizacionais.

A sequência para utilização do caso proposta abaixo pode ser livremente adaptada pelo professor, de acordo com seu plano de aula:

a. Leitura prévia do caso, por parte dos alunos;

b. Revisão e esclarecimento de conceitos básicos necessários à análise sistemática da situação apresentada;

c. Divisão dos alunos em pequenos grupos para discussão do caso e proposição de alternativas estratégicas ao jornal;

d. Apresentação da análise de cada grupo, discussão das alternativas no grande grupo e apresentação dos questionamentos sugeridos.

\subsection{Literatura recomendada para análise do caso}

BARNEY, J.B.; HESTERLY, W.S. Administração estratégica e vantagem competitiva: conceitos e casos. 3.ed. São Paulo: Pearson Prentice Hall, 2011. Capítulo 3, p. 57-71. 
MINTZBERG, H.; LAMPEL, J.; QUINN, J.B.; GHOSHAL, S. O processo da estratégia: conceitos, contextos e casos selecionados. 4. ed. Porto Alegre: Bookman, 2006. p. 112-122.

OLAVE, M.E.L.; AMATO NETO, J. Redes de cooperação produtiva: uma estratégia de competitividade e sobrevivência para pequenas e médias empresas. Gestão \& Produção, v.8, n.3, p.289-303, dez. 2001.

PORTER, Michael E. Competição: estratégias competitivas essenciais. 7. ed. Rio de Janeiro: Campus, 2002. Capítulo 1: Como as forças competitivas moldam a estratégia. p. 27-45.

\subsection{Referências utilizadas para elaboração do caso}

ALCADIPANI, R. O declínio dos jornais. GV Executivo, v. 6, n. 2, mar-abr. 2007.

F/Nazca diz que Brasil tem 81,3 milhões de internautas. 30 novembro 2010 <http://www.adnews.com.br/internet/110788.html> . Acesso em 02 de julho de 2011.

PORTER, M.E. How Competitive forces shape strategy. Harvard Business Review, p.137145, Nov-Dec.1988.

SANT'ANNA, L. O destino do jornal: A Folha de S.Paulo, O Globo e O Estado de S.Paulo na sociedade da informação. Rio de Janeiro: Record, 2008. 